\title{
VALUABLE INTEGRATIVE REVIEW OF HUMAN ETHOLOGICAL RESEARCH
}

\author{
Glenn Weisfeld \\ Department of Psychology, Wayne State University, Detroit, USA. \\ ad4297@wayne.edu
}

A Review of the Book

\section{Being Human: Bridging the gap between the sciences of body and mind}

By Gerhard Medicus. 2015

Translation by Norbert Hohl and Sonia Kleindorfer of the third German edition of

Was uns Menschen verbindet_Humanethologische Angebote zur Verständigung zwischen Leib-und Seelenwissenschaften.

Verlag für Wissenschaft und Bildung, Berlin, 212 pages.

ISBN 978-3-86135-584-7 (hardback, €30)

This monograph is by longtime ISHE member Gerhard Medicus, a psychiatrist who has taught human ethology at the University of Innsbruck for 25 years. It is volume 10 of a series, Am Zügel der Evolution, edited by Wulf Schiefenhövel and Judith Schuler.

The book attempts to bridge the humanities and human sciences but is more a review of research in human ethology. Chapter 1 introduces the four questions of Tinbergen, and shows that each question can be posed at various levels of analysis: molecules, cells, organs, the individual, the group, and society. Medicus describes how different disciplines address these questions for various behaviors. For example, affiliative behaviors are influenced by hormones and neurotransmitters, develop through cognitive advances in perspective taking, are adaptive for care of offspring and other functions, and evolved most extensively in mammals. He argues that this matrix highlights neglected questions that fall 
between disciplines and research programs. He stresses the value of cross-cultural research in understanding the etiology of particular diseases, many of which are rare in traditional cultures, e.g., myopia, obesity, colic, sudden infant death syndrome, and breast cancer. These conditions, incidentally, seem to be reduced by, respectively, abundant exposure to natural light, a diet rich in nutrients, frequent bodily contact, co-sleeping, and iterative pregnancies and lactation which reduce menstrual cycling.

Chapter 2 considers various epistemological questions regarding the humanities and sciences, such as the mind-body problem, falsifiability, levels of analysis, the role of practical reasoning, and scientific collaboration. Medicus discusses the naturalistic fallacy: adaptive behaviors are not necessarily socially or morally desirable, only that they tend to occur under certain conditions. Medicus asserts that "No theory is immune from improper application, nor can a theory be falsified because it is misused in practice. In this context, note that not only the improper application of a theory, but also ungained knowledge can have adverse effects" (p. 54, italics in original). Medicus adds, in Chapter 5, that the naturalistic fallacy "should not be stretched too far" (p. 105); social policies must be consistent with the facts of human nature or they will not be heeded.

He also addresses the moralistic fallacy: making inferences about natural phenomena from ideological assumptions. For example, our desire to condemn the harmful effects of human aggression has led to reluctance to recognize its evolved basis. Ethology has recognized the adaptive value of dominance aggression, defensive aggression, moralistic aggression, and warfare.

Chapter 3 deals with human cognition. Medicus explains how innate releasing mechanisms can become modified by operant conditioning. For example, a toad will initially snap at any small moving object such as a flying insect, but will learn to avoid wasps once stung. This chapter touches on esthetics: “... humans perceive movement that is practiced and energetically efficient as more harmonious, beautiful and worthy of imitation than the unpractised voluntary movements of beginners. The beauty of practiced movement has been culturally refined, as with dance and ballet" (p. 70). Note the adaptive value of finding efficient, graceful movements worthy of imitation. The chapter mentions the advantages of cooking in breaking down foods for easier and more thorough digestion, providing more calories for the burgeoning hominid brain. Cooking also allowed reduction in the size of the teeth and digestive tract, permitting further gains in bodily energy. Here Medicus' medical training serves him well, as it does in his analysis of the disadvantages of bipedalism. These include slower running speed, loss of grasping 
feet, spinal problems, narrower pelvic outlet, orthostatic hypotension, and varicose veins.

Chapter 4 deals with parental behavior. Here emotional expressions get their due. Friendly behavior, which probably originated with parental care, attracts social partners, enhances trust, and inhibits aggression. Similarly, candor and transparent behavior foster trust (Chapter 5). The begging gesture of chimpanzees is observed in humans too, probably because it is a "serviceable associated habit" (Darwin, 1998) of anticipation of being handed something. Also covered are not only the infant schema but also the endearing female schema and the intimidating male schema.

Medicus' claim that the commonly groomed body parts of children become erogenous zones of adults may not be completely correct-mouth and genitals yes, but ear canal? Wouldn't grooming be directed at body cavities and interstices where debris can accumulate, but sexual stimulation at structures related to pleasurable arousal and relaxation, such as the breasts (nursing releases oxytocin) and the nape and back (which are stimulated in female mammals during mounting)?

Chapter 5 concerns morality. Theory of mind is discussed, and Medicus emphasizes the role of emotions in moral behavior, including those of pride, shame, guilt, remorse, and regret. The question of free will is raised. The author suggests, interestingly, that philosophers generally credit humans with having more freedom than psychologists-and moreso neurologists--do. He argues that we must have free will because there are opposing instincts to decide between. But one can easily imagine a neural mechanism for prioritizing competing motivations. Think of the toad forgoing a meal of a wasp in order to avoid being stung. Maslow's hierarchy of needs in humans implies that the process of taking these decisions has an evolved basis and also has the potential to be modified by experience.

Chapter 6 concerns resource distribution. Medicus points out the benefit of dominance hierarchies in regulating resource allocation. The treatment of dominance hierarchies is particularly informative. In many primates daughters are backed up by the mother. Ranks are sometimes based on social competence, as in elephants, and not just on aggression. Ranks sometimes depend on the context: relative ranks. Dominant individuals receive more attention, or monitoring. Reconciliation, initiated by the victor, enhances group solidarity. Another provocative thought is that there is no satiation effect for power or dominance, 
and feelings of superiority can be magnified inordinately by the subservience of subordinates.

Medicus describes the right of possession of the first animal to claim a territory or to secure an object. One might add that these unspoken norms are enforced by the threat of retaliation, or rage reaction. Chapter 11 mentions norms regulating dominance competition, including failure to submit when defeated and escalation of ritualized fighting. In humans, violations of various social norms lead to moralistic aggression. This comparative treatment shows the continuity of angry aggression between animals and humans.

A wealth of interesting information comes in Chapter 7 on sex differences. The benefits of sexual reproduction are explained, although the benefits of asexual reproduction, found in about one-third of species, are overlooked. As in other species, women are attracted to dominant males. By displaying dominance, a man can advertise his capacity to protect a woman and her children, and to confer his social rank on her. Medicus notes that pair-bonding female hominoids gain little by soliciting extra-pair sex partners, so they lack conspicuous vulvae at estrus. He points out that sexual promiscuity incurs the risk of sexual disease. Male body size is favored not only by mate competition as in promiscuous species but also by the need for defensive aggression, warfare, hunting, and even house construction. Medicus observes that women who conceal their sexual acts can avoid provoking jealous attacks and evoking unwanted sexual attention, thereby enhancing their mate choice on both counts. Coy behavior allows a woman time to appraise the man before making a reproductive commitment.

Chapter 8 concerns the biogenetic law. Medicus sensibly calls it a rule rather than a law, because of its many exceptions. Some exceptions can be understood as arising from heterochrony: evolved tinkering with developmental sequences and process durations. The biogenetic "rule" has many uses, including understanding various developmental abnormalities as being cases of reversion to ancestral forms as manifested by incomplete development. For example, bicornuate (two-horned) uterus in women is a throwback to the form of the normal uterus in primordial mammals such as rodents. Likewise, supernumerary human nipples mimic the earlier mammalian form in species with litters. The rule also explains terminal addition, the tendency of evolutionary changes to occur relatively late in ontogeny, when they are less disruptive. Thus, abnormalities in higher cognitive functions, frequently involving the prefrontal cortex, are common because they are late to develop and are not lethal. Mutations affecting the atavistic brainstem, by contrast, are often fatal and so are seldom seen in patients. Medicus asserts that 
the construction of later forms (ontogenetically and phylogenetically) on top of earlier ones occurs more for anatomical traits than behavioral ones.

In Chapter 10, Medicus reviews research on attachment, including the "quiet alert" bonding period immediately postpartum, postpartum depression, caesarean section, and allomothering. Much of the cross-cultural research cited here and elsewhere is by Schiefenhövel and Medicus himself. Medicus distinguishes the neonate's multimodal recognition of the mother from the infant's subsequent motoric ability to approach her when they are separated. He also compares adolescent detachment from parents in traditional and modern cultures. Various attachment disorders are explained as being deviations from normal functioning.

Being Human provides a valuable overview of human ethological research, especially work published in German. A book review cannot do justice to the intricacies of this work. One might quibble about some of the statements, such as male and female homosexuality having similar causes, but the scope and integrated thought are admirable. Being Human underscores the importance of evolutionary thinking at all levels of analysis, and the utility of interdisciplinary knowledge.

\section{ABOUT THE AUTHOR}

Glenn Weisfeld wrote Evolutionary principles of human adolescence; co-edited, with Nancy Segal and Carol Weisfeld, Uniting psychology and biology; co-edited, with Peter LaFreniere, Evolutionary science of human behavior; and is co-editing, with Carol Weisfeld and Lisa Dillon, Psychology of marriage. He has also investigated dominance, pride and shame, humor, inbreeding avoidance, and play.

\section{REFERENCE}

Darwin, C. (1998). The Expression of the emotions in man and animals (3rd ed.). New York: Oxford University Press. 